\title{
Formation of porous silica nanoparticles at higher reaction kinetics
}

\author{
Manuel Meier *, Julian Ungerer, Mira Klinge, Hermann Nirschl \\ Institute of Mechanical Process Engineering and Mechanics, Karlsruhe Institute of Technology (KIT), Campus Sued, Strasse am Forum 8, 76131 Karlsruhe, Germany
}

\begin{abstract}
A B S T R A C T
This work deals with the analysis of the formation of porous spherical silica particles without adding any surfac tants. The use of a wide range of measurement techniques allows the particle formation process to be tracked with regard to the particle size, structure and density. The analysis of the pore inlet diameter distribution based on the Kelvin effect indicates a change in the particle structure at higher reaction temperatures. Measure ments with UV Vis spectroscopy and TEM showed a collapse toward smaller particle sizes within the first mi nutes of the reaction. The higher the synthesis temperature, the more pronounced the collapse is and the
\end{abstract}

Keywords:

Porous silica

Nitrogen adsorption

In-situ characterization

UV-Vis

SAXS

\section{Introduction}

In the last decades, the demand for silica nanoparticles with well defined particle sizes, shapes and particle size distributions has in creased to meet new application requirements for catalysis, chemo mechanical polishing, membrane technologies, sensing or biomedical applications [ 1 7]. One aspect of research that has grown significantly in recent years is the need for mesoporous silica nanoparticles (MSNs) for biomedical applications. Many researches use surfactants to create porous structures with various length scales [ 814 14. Considering litera ture that studies the formation of silica particles from alkoxides, there is already evidence that the Stöber process itself [15] may produce porous spherical silica particles. Among others, Keefer [16] and Schaefer [17, 18 ] investigated the particle formation process through synchrotron ra diations in the early eighties. Due to its non invasive character, the SAXS technique proved to be well suited to study the first steps of the particle formation process. They and other co workers proposed the poisoned Eden model, which describes a reaction limited growth at slow reaction rates resulting in compact smooth particles. Under mild reaction condi tions mass fractal clusters or particles with rough surfaces can be pro duced. In the late nineties, Boukari et al. $[19,20]$ proposed a gradual densification process of the silica nanoparticles from mass fractals to surface fractals to non fractal, compact spheres with progressing

Abbreviations: $D_{k}[\mathrm{~nm}]$, inlet pore diameter; $\left.D_{s f}\right]$ ], surface fractal dimension; $\gamma\left[\mathrm{Nm}^{1}\right]$, surface tension; $f$ [ ], frequency distribution; $I(q)$ [a.u.], scattering intensity; $\lambda_{\text {char }}[\mathrm{nm}$ ], characteristic wavelength; ${ }^{p} / p_{0}\left[\right.$ ], relative vapor pressure; $q\left[\mathrm{~nm}{ }^{1}\right]$, scattering vector; $R$ $\left[\mathrm{kg} \mathrm{m}^{2} \mathrm{~s}^{2} \mathrm{~mol}^{1} \mathrm{~K}^{1}\right]$, universal gas constant; $R_{S \mathrm{~m}}[\quad]$, surface roughness; $\rho\left[\mathrm{g} \mathrm{cm}^{3}\right]$, density; $S_{m}\left[m^{2} g{ }^{1}\right]$, specific surface area; $\sigma_{\text {rel }}[\%]$, relative standard deviation; $T_{r}\left[{ }^{\circ} \mathrm{C}\right]$, reaction temperature; $T_{h}\left[{ }^{\circ} \mathrm{C}\right]$, heating temperature; $V_{m}\left[\mathrm{~m}^{3} \mathrm{~mol}{ }^{1}\right]$, molar volume.

* Corresponding author.

E-mail address: manuel.meier@kit.edu (M. Meier) reaction time. The transition of the individual growth stages, however, shows no effect on the particle size, which increases steadily with in creasing reaction time. Conversely, Bailey et al. showed that a transition from the individual growth stages can have an influence on the particle size [21]. On the basis of cryo TEM images, they describe a collapse of the particles in a very early growth stage which results in a sudden in crease in the density of the particles. As a possible explanation, he pro posed that the solubility of micro gel clusters is exceeded at a certain particle size, resulting in a collapse and, subsequently, a densification of the particle. Dealing with polymer gels, Brinker and Scherer [22] de scribed a collapse of the gel network by desiccation in 1985. But if this does not occur, they suggested a continuous collapsing and crosslinking, resulting in porous structures in the gel network. This behavior has al ready been described by Iler [23] for gel structures in colloidal systems in 1955. To obtain a deeper understanding about the particle formation process, molecular dynamic studies on accepted growth mechanisms have become increasingly important in recent years (e.g. [24 28]). Strong emphasis lies on the nucleation, changes in particles density as well as the long term behavior over several hours to days. However, most of these works focus on modeling the growth of compact particles instead of porous structures. Not least because the metrological imple mentation to obtain required in situ information on the particle forma tion process involves some challenges in process engineering.

In order to produce particles with enlarged surfaces, a comparatively high reaction rate must be used. This can be achieved by high precursor or catalysts concentrations, which leads to large particles typically of several hundred nanometers in size (e.g. [29]). To avoid any influence of sedimentation, the particle size must be kept below $500 \mathrm{~nm}$ by in creasing the reaction temperature [30]. Thus, the synthesis of silica nanoparticles using the Stöber method is typically carried out in a con tinuously stirred three neck flask with a reflux condenser to avoid 
ammonia evaporation at elevated temperatures. Since most measuring cells are not equipped with a stirrer or upgradable with a reflux con denser, this experimental setup is disadvantageous for in situ measure ments. The application of a higher pressure would indeed prevent the evaporation of ammonia, but in turn places higher demands on the syn thesis apparatus and the measurement cell. Another aspect that needs to be taken into consideration is the required device specific measure ment time. At measuring times of a few seconds, only sufficient mixing of the solution is required. Measuring times of a few minutes, however, may require the use of a continuous reactor system in which the resi dence time in the measuring cell remains constant. In order to meet these different requirements, a modified Stöber synthesis route was de veloped in a previous work [31]. This step was one of the keys to convert the synthesis into a continuous reactor system under ambient pressure.

\section{Experimental}

\subsection{Sample preparation}

The Stöber process is based on the hydrolysis of tetraethyl orthosilicate (TEOS) (for synthesis, co. Merck, Darmstadt) with de mineralized water in ethanol (denatured, $\geq 99,8 \%, c o$. Carl Roth, Karls ruhe) followed by a condensation reaction, leading to the formation of silica. In addition, ethanolamine (for synthesis, co. Merck, Darmstadt) serves as a basic catalyst. The reaction mixture was separated into two stock solutions: stock solution 1 contained half of the amount of ethanol and the entire amount of TEOS, stock solution 2 contained half the amount of ethanol and the entire amount of water and ethanolamine. The particles were prepared with $0.2 \mathrm{molL}^{-1}$ ethanolamine, 0.22 molL $^{-1}$ TEOS and 3 moll $^{-1}$ water. Both solutions were preheated sep arately and mixed in a reaction vessel to start the reaction. For synthesis in a continuous reactor system (see Fig. 1), the reaction solutions were filled into 2 syringes (perfusor syringe $50 \mathrm{ml}, \mathrm{co}$. BBraun, Germany) and pumped (pump 33 dual syringe pump, co. Harvard Apparatus, United States) through a heating zone. An in house developed mixer ensured a sufficient mixing for at least 45 seconds of the solutions for flow rates up to $1.4 \mathrm{mlmin}^{-1}$. A heated reaction tube provided the required residence time and is connected to the SAXS device.

\subsection{Sample characterization}

To determine the final particle diameter with a TEM CM12 (co. Philips, Netherlands) samples were taken after 360 minutes. They were diluted with ethanol (dilution factor $=1: 20$ ) at $20^{\circ} \mathrm{C}$ and air dried on a TEM grid. In addition to an optical assessment of the particles, the analysis involved the evaluation of the density distribution of at least 500 particles using the software ImageJ.

The determination of the surface area based on nitrogen adsorption according to Brunauer Emmett Teller (BET) were performed using an Autosorb 1 (co. 3P Instruments, Germany). To describe the proportion of the interior structure $S_{m \text {,interior }}$ in the total surface area $S_{m, \text { total }}$, the

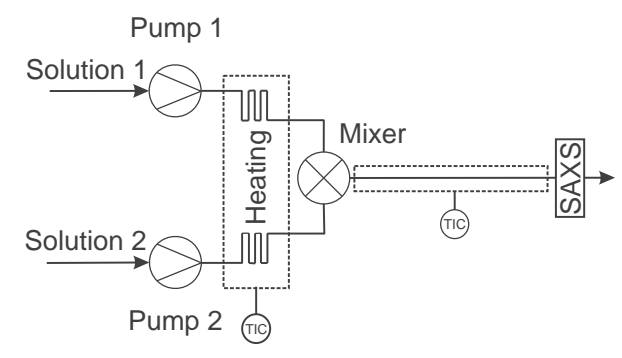

Fig. 1. Scheme of the continuous reactor system. surface area of a smooth sphere $S_{m \text {,sphere }}$ has been calculated by

$S_{m, \text { sphere }} \frac{6}{\rho d_{p}} 10^{3}$

where $\rho$ is the density of silica in $\mathrm{gcm}^{-3}$ and $d_{p}$ the particle diameter in $n m$. The surface roughness $R_{S m}$ describes the deviation of the total sur face area from the surface area of a smooth sphere (see Eq. 2). The higher the proportion of the interior structure in the total surface area, the higher is the surface roughness.

$$
R_{S m} \frac{S_{m, \text { total }}}{S_{m, \text { sphere }}}
$$

To obtain more information on the interior particle structure, an analysis of the pore inlet diameter distribution is needed. The expected pore inlet diameter of less than $5 \mathrm{~nm}$ (e.g. [32]) make it difficult to mea sure the distribution. However, an approach that allows statements about the distribution deals with the sample preparation before the BET measurement. At the end of the synthesis all pores are filled with ethanol. The more pores can be drained by evaporation of ethanol, the higher the specific surface area. How much liquid evaporates depends on the heating temperature. This behavior is based on the Kelvin effect, whereby the vapor pressure at concave surfaces is lower than that over a flat phase interface. Thus, the higher the heating temperature, the smaller is the pore inlet diameter that can be made accessible for ni trogen adsorption. A relationship between the smallest pore diameter $D_{k}$ that can be accessed at a given temperature $T$ in $K$ and relative vapor pressure $\left(p / p_{0}\right)$, is given by the Kelvin equation

$D_{k}-\frac{4 \gamma V_{m}}{R T \ln \left(p / p_{0}\right)}$

where $\gamma$ is the surface tension, $V_{m}$ is the molar volume of the liquid and $R$ is the universal gas constant [33]. The heating temperature $T_{h}$ was var ied in a range between 60 and $350^{\circ} \mathrm{C}$ at 50 mbar for 16 hours.

The samples for UV Vis spectroscopy (flame miniature spectrometer, co. Ocean Optics, United States) were prepared in $2 \mathrm{~mL}$ conical centrifuge tubes (co. VWR, Germany) and after mixing transferred to a quartz glass measurement cell (light path $10 \mathrm{~mm}$, co. Hellma Analystics, Germany).

SAXS measurements were performed with an in house developed lab scale SAXS/WAXS device described in our previous work [34 40]. The experimental setup consists of a $1.2 k W \mathrm{Cu} K \alpha \mathrm{X}$ ray source, a focus ing slit shaped $\mathrm{X}$ ray beam realized through a multilayer focusing opti cal element (Göbel mirror), a block slit collimator system and a Dectris ${ }^{\circledR}$ Pilatus $100 \mathrm{~K} \mathrm{~S}$ on line detector. The detector has a dimension of 83 by $33 \mathrm{~mm}$ with a pixel size of $0.172 \mathrm{~mm}$. The slit shaped $\mathrm{X}$ ray beam is re corded along the height of the detector and the scattering is detected along the length. Analyzing scattering data, the intensities of each pixel are integrated over the height of the $X$ ray beam and then plotted over the detector length. To correct the error of a slit shaped $X$ ray beam, the background corrected scattering data were desmeared using the direct method according to Singh et al. [41]. The scattering data were recorded for 300 seconds. The intensity $I(q)$ obtained by means of SAXS was measured as a function of the scattering vector $q$ with $q=4 \pi / \lambda \cdot \sin (\theta / 2)$. Here, $2 \theta$ is the scattering angle and $\lambda=$ $0.154 \mathrm{~nm}$ the wavelength of the used $\mathrm{Cu} \mathrm{K} \alpha \mathrm{X}$ ray. The primary particle size as well as the fractal dimension of the surface $D_{s f}$ were obtained by the unified fit model [42].

\section{Results and discussion}

\subsection{BET analysis}

To obtain a first insight into the influence of the reaction tempera ture on particle size, shape and surface properties, TEM images were 
taken after 360 minutes reaction time (see Fig. 2). All samples were pre pared in reaction vessels and at reaction temperatures between 30 and $60^{\circ} \mathrm{C}$. In addition to the expected reduction of the particle diameter, the images show a rougher particle surface and a less spherical shape at higher reaction temperatures. However, statements about the internal structure of the particles are not possible.

The surface area determination with nitrogen adsorption according to Brunauer Emmett Teller (BET) has been proved to be a well suited measurement technique $[43,44]$ to gain information about internal structures. A graphical overview of the specific surface area $S_{m}$ (dark grey bars) and the particle sizes derived from TEM images (grey dots) depending on the synthesis temperature is given in Fig. 3. The higher the synthesis temperature, the higher is the specific surface area. The values are well above the calculated specific surfaces for smooth spheres (white bars). Table 1 shows the obtained results in detail. For a reaction temperature $T_{r}$ between 25 and $40^{\circ} \mathrm{C}$ the surface roughness $R_{S m}$ remains on a constant level at approximately 3 , indicating a three times higher surface area typically obtained for smooth particles. The almost constant level leads to the assumption that the particle structure does not change dramatically in this temperature range. At higher reaction temperatures, an increase in the surface roughness up to 4.3 at $60^{\circ} \mathrm{C}$ can be observed. Thus, the characteristics of the particle structure must have changed.

Since the surface roughness is calculated solely from the obtained surface area, it can not distinguish which proportion is due to roughness at the surface and which due to pores in the interior. Thus, an analysis of the pore inlet diameter distribution based on the Kelvin effect has been performed (see chapter 2.2). The heating temperature $T_{h}$ was gradually increased from 60 to $350^{\circ} \mathrm{C}$ and the accessible surface was measured with the BET. In a temperature range between 60 and $250^{\circ} \mathrm{C}$ for the heating, the specific surface area increased steadily for all reac tion temperatures. At temperatures higher than $300^{\circ} \mathrm{C}$, changes in the linear behavior can be observed: Whereas only a minimal increase of the specific surface area can be detected at a reaction temperature of $40^{\circ} \mathrm{C}$, an abrupt increase takes place at a reaction temperature of $60^{\circ} \mathrm{C}$ (see Fig. 4 ).

A graphical overview of the frequency distribution $f\left(S_{m}\right)$ of the spe cific surface area dependent on the pore inlet diameter is given in Fig. 5. Table 2 shows the exact results including the heating
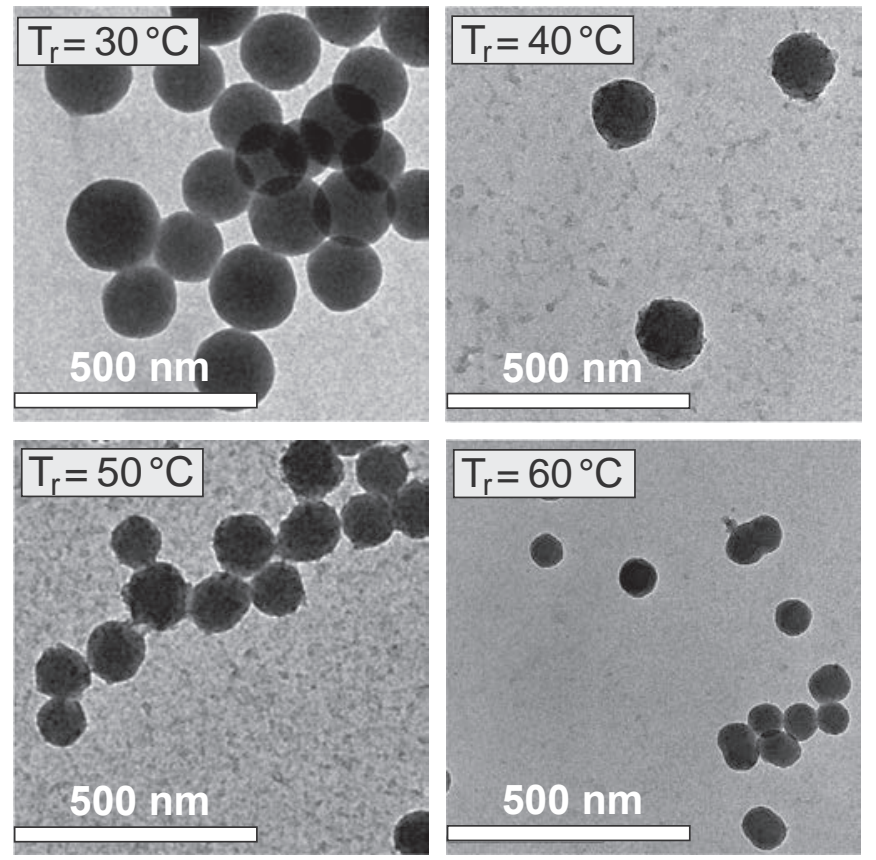

Fig. 2. TEM images of silica nanoparticles prepared with 0.2 molL ${ }^{1}$ ethanolamine, 0.22 molL ${ }^{1}$ TEOS and 3 molL ${ }^{1}$ water at various reaction temperatures $T_{r}$ after 360 minutes reaction time.

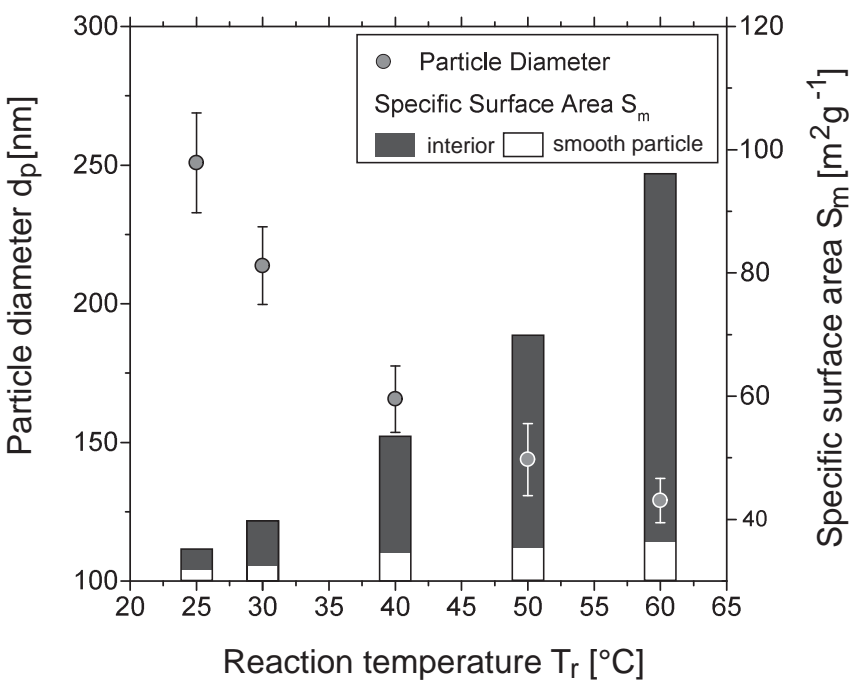

Fig. 3. Particle size measured by means of TEM (grey dots) and specific surface area by means of BET (dark grey bars) depending on the reaction temperature $T_{r}$. The white bars represent the portion of the calculated surface area of a smooth sphere. In preparation for BET measurement, the samples were heated at $350^{\circ} \mathrm{C}$ and 50 mbar for 16 hours.

temperatures corresponding to the pore inlet diameter. The samples synthesized at a reaction temperature of 25 and $40^{\circ} \mathrm{C}$ indicate a fre quency of two thirds for an inlet diameter larger than $2.3 \mathrm{~nm}$ (see Table 2). Focusing on the results in range between 1.35 and $2.3 \mathrm{~nm}$, par ticles synthesized at $25^{\circ} \mathrm{C}$ show a peak at $1.8 \mathrm{~nm}\left(f\left(S_{m}\right)_{25^{\circ} \mathrm{C}, 1.8 \mathrm{~nm}}=14.8\right.$ \%), the samples synthesized at $40^{\circ} \mathrm{C}$ at $1.5 \mathrm{~nm}\left(f\left(S_{m}\right)_{40^{\circ} \mathrm{C}, 1.5 \mathrm{~nm}}=12.8 \%\right)$. Thus, a slight shift to smaller pore inlet diameters at higher reaction temperatures can be observed. The samples synthesized at $60^{\circ} \mathrm{C}$ show a drastic shift to smaller pore inlet diameters. The overall frequency for the pore inlet diameters larger than $2.3 \mathrm{~nm}$ is only a half and a high peak can be observed at $1.5 \mathrm{~nm}\left(f\left(S_{m}\right)_{60^{\circ} \mathrm{C}, 1.5 \mathrm{~nm}}=26.0 \%\right)$.

\subsection{TEM analysis}

The results indicate the existence of porous structures but also a shift to smaller pore inlet diameters at higher reaction temperatures. Since BET measurements can only be conducted with the final product of the synthesis, there is a lack of information which mechanism creates or changes the porous structures. In order to obtain information about the particle growth, images were taken with TEM. In terms of in situ analysis, a high dilution is required to stop the reaction and avoid changes in the particle structure during the sample preparation (e.g. drying). For the particle formation process of silica, many studies pro pose low density ever elusive primary particles followed by an addition of soluble monomers (e.g. [45 47]). Their proof turns out to be difficult because they have neither a high contrast nor a sufficient scattering behavior due to the slight difference in density to the sur rounding media [21]. In consequence, the low particle number on each TEM grid due to high dilution as well as a low contrast require camera settings with a high resolution and a low energy beam focused

Table 1

Particle properties obtained by TEM images and BET measurements.

\begin{tabular}{lllllll}
\hline & & & \multicolumn{3}{l}{$\left.\boldsymbol{S}_{\boldsymbol{m}} \boldsymbol{m}^{\mathbf{2}} \mathbf{g}^{\mathbf{1}}\right]$} \\
\cline { 4 - 6 }$\left.T_{r}{ }^{\circ} \mathrm{C}\right]$ & $d_{p}[\mathrm{~nm}]$ & $\sigma_{\text {rel }[\%]}$ & Total & Interior & Sphere & $R_{S m}[\quad]$ \\
\hline 25 & 250.8 & 7.2 & $\mathbf{3 5 . 2}$ & $\mathbf{2 3 . 7}$ & $\mathbf{1 1 . 4}$ & 3.1 \\
30 & 213.7 & 6.6 & $\mathbf{3 9 . 7}$ & $\mathbf{2 6 . 3}$ & $\mathbf{1 3 . 4}$ & 3.0 \\
40 & 165.6 & 7.2 & $\mathbf{5 3 . 5}$ & $\mathbf{3 6 . 2}$ & $\mathbf{1 7 . 3}$ & 3.1 \\
50 & 143.8 & 8.5 & $\mathbf{6 9 . 8}$ & $\mathbf{4 9 . 9}$ & $\mathbf{1 9 . 9}$ & 3.5 \\
60 & 129.0 & 6.2 & $\mathbf{9 6 . 0}$ & $\mathbf{7 3 . 9}$ & $\mathbf{2 2 . 2}$ & 4.3 \\
\hline
\end{tabular}




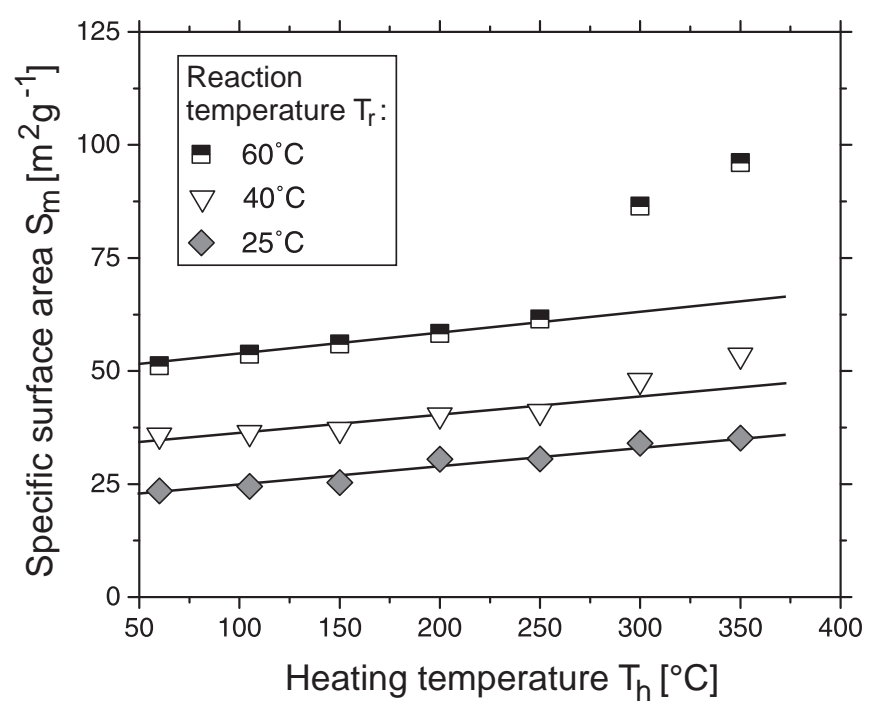

Fig. 4. Influence of the sample preparation for the nitrogen adsorption on the specific surface area at various heating temperatures $T_{h}$ at 50 mbar. The heating time was set to 16 hours.

on each single particle. This makes it difficult to record a large number of particles on one TEM grid. Thus, the associated particle size should rather be seen as a reference, which is why the specification of exact values and the standard deviation have been omitted. TEM images obtained for various time steps of particles synthesized at $50^{\circ} \mathrm{C}$ are shown in Fig. 6 . The particle size increases within the first 10 minutes followed by a decrease in particle size at 15 minutes. Afterwards, the particle sizes rise again. Nevertheless, in spite of the deficiencies men tioned above, a shrinking of the particles during the particle formation process can be observed.

\subsection{UV Vis analysis}

To validate the results obtained by TEM, a second measurement technique has to be taken in account. The recording of UV Vis spectra has already proven to be a fast and easy method to measure in situ the size and concentration of various kinds of nanoparticles, e.g. for gold [48 51], silver [52 54] or silica [55, 56]. The physical basis is the

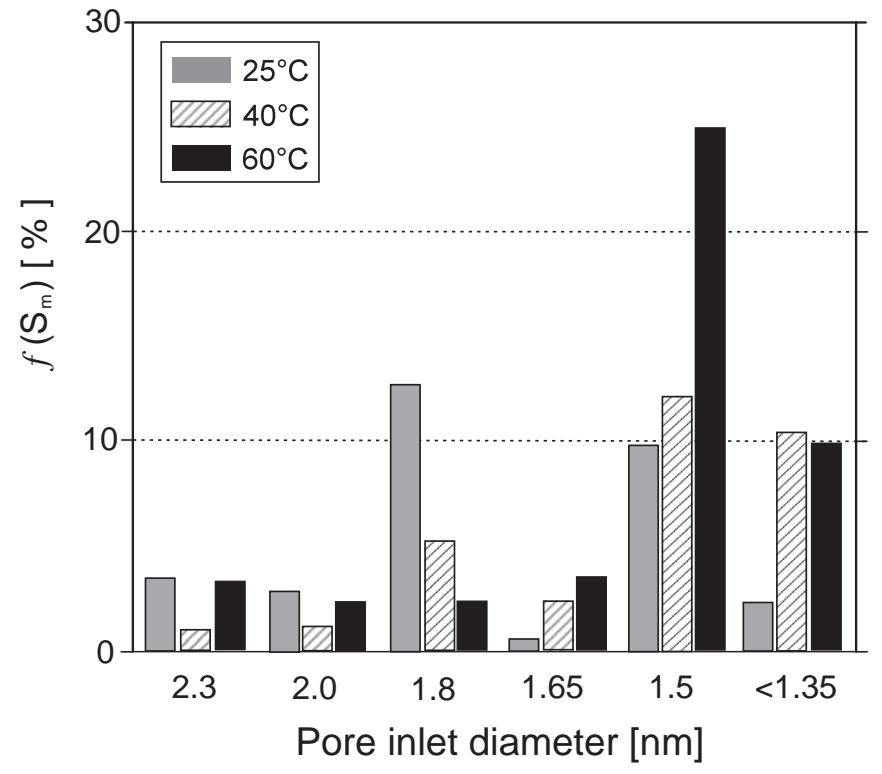

Fig. 5. Frequency distribution of the pore inlet diameter obtained by the Kelvin equation from the specific surface area.

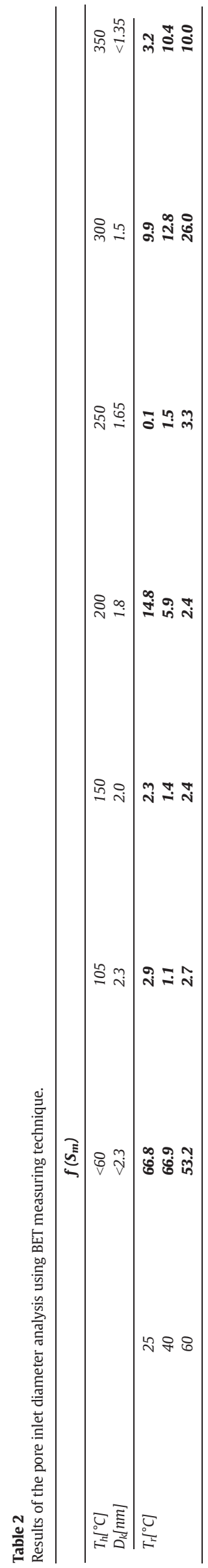



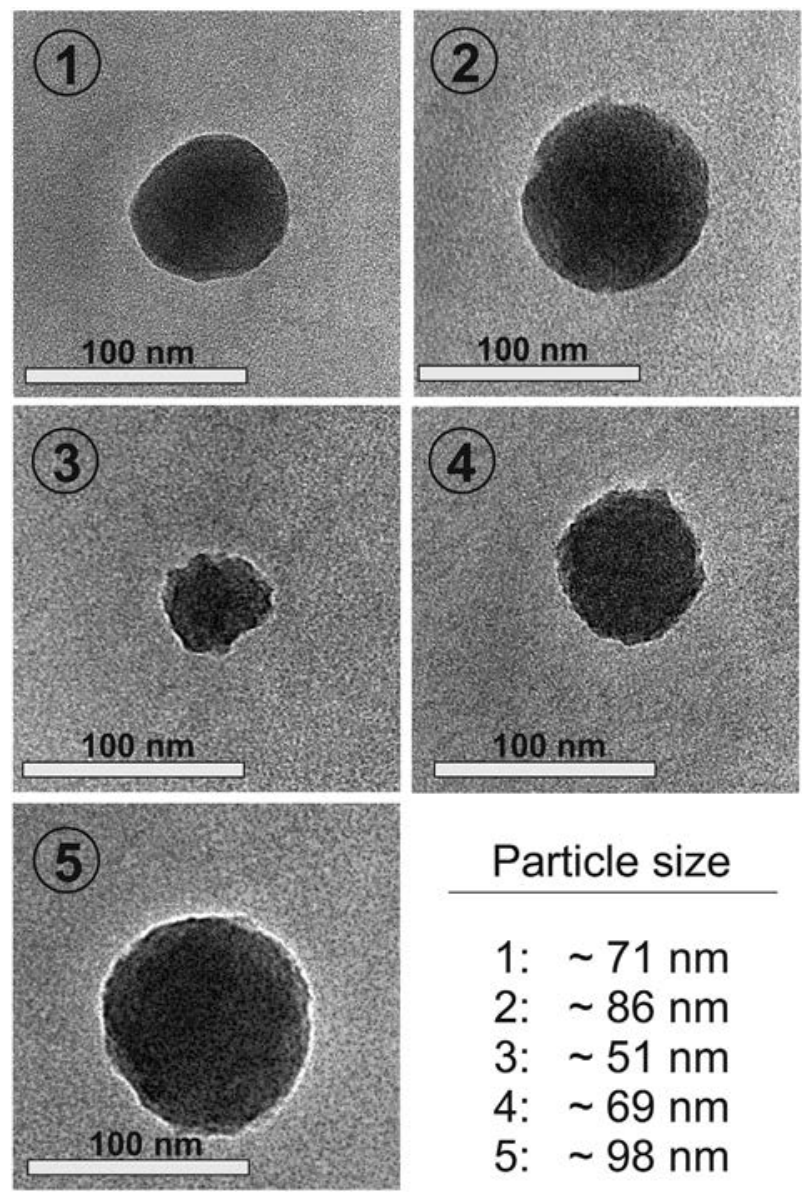

Fig. 6. TEM images of particles synthesized at $50^{\circ} \mathrm{C}$ for various time steps: 5 (Pict. 1), 10 (Pict. 2), 15 (Pict. 3), 20 (Pict. 4) and 30 (Pict. 5) minutes.

existence of an absorption maximum at a characteristic wavelength due to a surface plasmon assisted field amplifier character of metal oxide nanoparticles. The wavelength and the height of the maximum depends on the dielectric constant of the particles and the solvent as well as the size, concentration and the geometry of the particles [57]. A UV Vis spectra of silica in ethanol illustrated as an inlet as well as the character istic wavelength $\lambda_{\text {char }}$ of the absorption maximum obtained for particles synthesized at a reaction temperature of $50^{\circ} \mathrm{C}$ depending on the reaction time are given in Fig. 7. Just like in the TEM images (the numbers show the sampling time for the TEM images), a shift to smaller characteristic wavelengths and thus to smaller particle sizes can be observed at a reac tion time of 15 minutes. As the reaction progresses, the particle size in creases steadily. Within the first 10 minutes, no increase in particle size can be detected due to the low concentration. These results also in dicate the observation of particle shrinking within the first few minutes of particle growth. However, an unambiguous assignment of the charac teristic wavelength to a specific particle size is not possible since the res onance is affected not only by the size of the particle but also by the surface structure. A comparison of these results with the results ob tained for compact silica with smooth surfaces suggests that the parti cles measured here are in a size range between 40 and $80 \mathrm{~nm}$.

To characterize the influence of the reaction kinetic on the first stage of the particle formation process, the change in the characteristic wave length dependent on the reaction temperature $T_{r}$ in a range between 25 and $60^{\circ} \mathrm{C}$ have been monitored (see Fig. 8). Fig. 9 shows the trends for the time of collapse $t_{\text {collapse }}$ (black squares) and the difference in the characteristic wavelength $\Delta \lambda_{\text {char }}$ (grey circles) between the start of the reaction and the collapse for each reaction temperature. The higher the reaction temperature, the sooner the collapse takes place and the

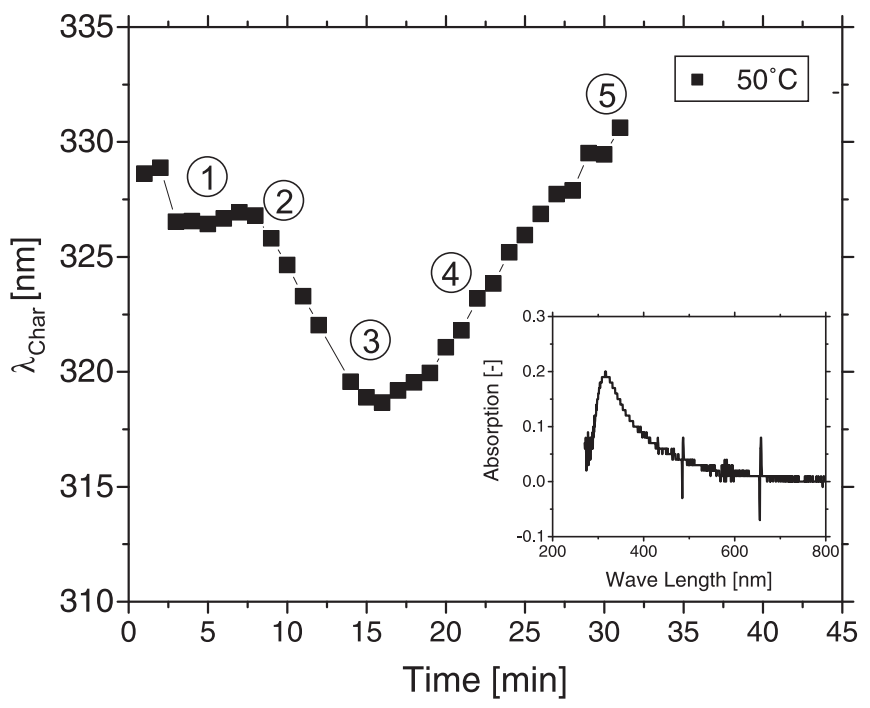

Fig. 7. UV-Vis spectra of silica in ethanol (inlet) as well as the characteristic wavelength $\lambda_{\text {char }}$ of the absorption maximum obtained for particles synthesized at $50^{\circ} \mathrm{C}$ dependent on the reaction time. The numbers show the sampling time for the TEM images.

higher is the difference in the characteristic wavelength. The time to col lapse indicates an exponential progression, whereas $\Delta \lambda_{\text {char }}$ indicates a linear increase. The decrease in time to collapse with increasing temper ature is easily comprehensible, considering the increasing reaction kinetics. The steep decrease in the difference of the characteristic wave length towards lower temperatures is much more remarkable. With the proposed explanation by Bailey that the solubility of micro gel clusters is exceeded at a certain particle size resulting in a collapse, the differ ence in the characteristic wavelength should be more or less the same for all reaction kinetics. In consequence, there is another effect which influences the decrease of the particle size. In a previous work we discussed the existence of pores in silica nanoparticles, which are inac cessible for nitrogen adsorption, even at lower reaction kinetics [58]. This leads to the assumption that prior the collapse smaller pores are not completely filled but coated in such a way that they are inaccessible for nitrogen adsorption. The coating of inner pores stabilizes the micro gel clusters resulting in a less pronounced collapse. Thus, this assump tion would explain both, a decrease in small pores obtained for the fre quency distributing of the pore inlet diameter for particles synthetized

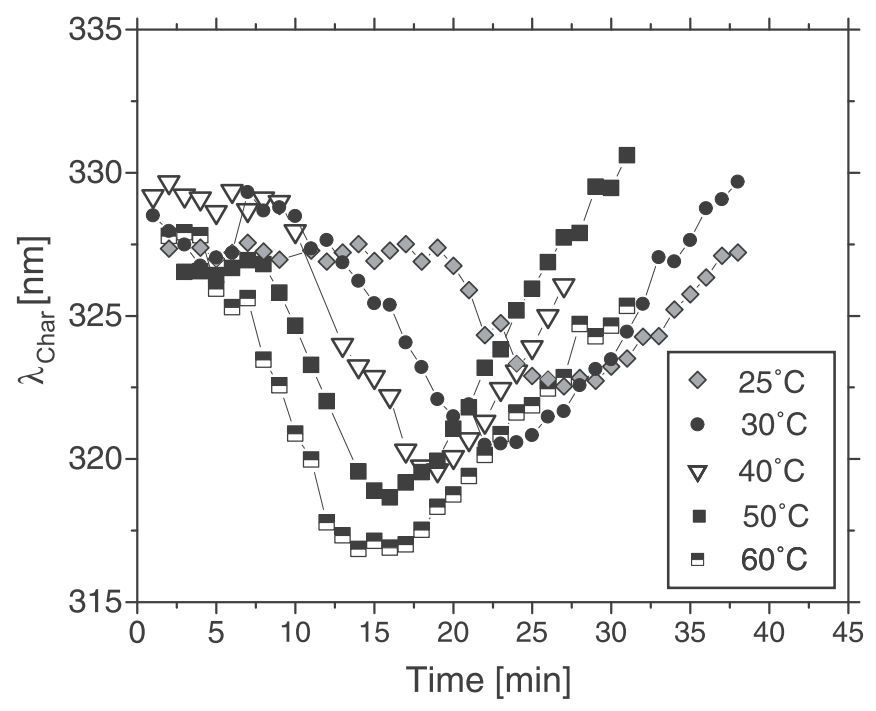

Fig. 8. Characteristic wavelength $\lambda_{\text {char }}$ dependent on the reaction time obtained at various reaction temperatures. 


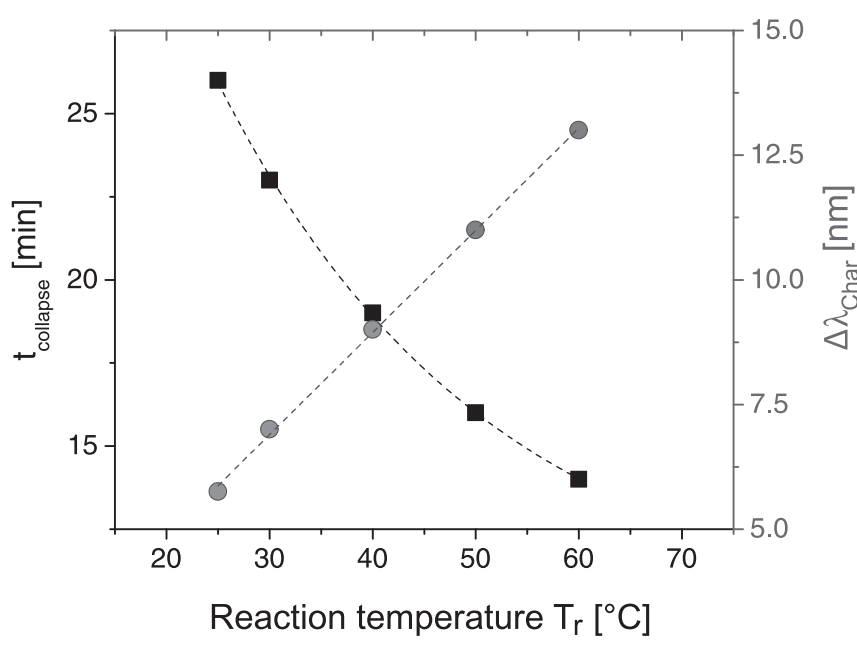

Fig. 9. Trends of the time of collapse $t_{\text {collapse }}$ (black squares) and the maximum difference in the characteristic wavelength $\Delta \lambda_{\text {char }}$ (grey circles) over the reaction temperature $T_{r}$

at low reaction temperatures and a more pronounced cluster collapse at higher reaction temperatures. It seems reasonable that with lower reaction kinetics the internal densification progresses so far that no collapse is recognizable. This can explain why only in a few works the collapse has been reported so far.

\subsection{SAXS analysis}

However, the particle collapse as well as an ongoing coating of cav ities inside the particle should lead to a change in particle density. SAXS measurements are well suited to detect changes in particle density, but in situ measurements have much higher demands on the experimental setup. The low particle concentration in the first minutes of reaction re quires measurement times up to several minutes to ensure a sufficient signal to noise ratio. To meet this requirement, a continuous reactor system has been connected to the SAXS device. The difference in charac teristic wavelength by means of UV Vis spectroscopy was used to vali date the performance of the continuous reactor system in terms of mixing, residence time and temperature control (see chapter 2.1). The results of syntheses using a batch reactor system (black squares) and the continuous reactor system (white rhombi) are shown in Fig. 10.

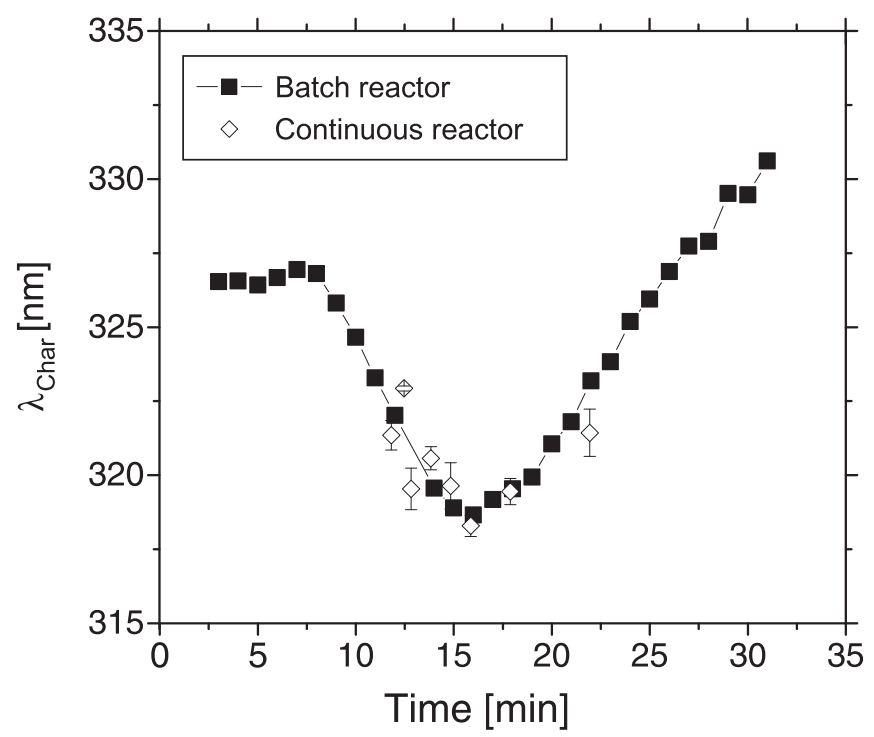

Fig. 10. Validation of the continuous reactor system based on the characteristic wavelength $\lambda_{\text {char }}$ obtained by UV-Vis spectroscopy at $50 .{ }^{\circ} \mathrm{C}$
To validate the assumption that the interior structure becomes more compact at lower reaction kinetics, the change in $\mathrm{X}$ ray scattering before and after the collapse was monitored. Due to setup specific limitations in the flow rate, the available time frame for the reaction monitoring was between 12 and 22 minutes. A reaction temperature has been chosen at which the collapse in particle size was in this time frame (here $60^{\circ} \mathrm{C}$ ) and shortly thereafter (here $30^{\circ} \mathrm{C}$ ). The obtained time resolved SAXS data are given in Fig. 11. Analyzing the synthesis performed at $30^{\circ} \mathrm{C}$, no scattering data was obtained within the first 19 minutes (see Fig. 11a). From minute 20on, the scattering intensity increases slowly. At a reaction temperature of $60^{\circ} \mathrm{C}$ no scattering data were obtained within the first 15 minutes, as well (see Fig. 11b). But from minute 16 on a clear measure ment signal can be observed, which gains in intensity with increasing re action time. The fractal dimension of the surface $D_{s f}$ decreases from 2.9 to 2.1 as the reaction time progresses, describing a gradual densification process from mass fractals to surface fractals to non fractal, compact spheres [59]. The scattering data obtained for a reaction time of $22 \mathrm{mi}$ nutes were fitted using the unified fit model for polydisperse compact spheres (dashed lines). The particles show a particle size of $44.2 \mathrm{~nm}$ and a relative standard deviation of $22.5 \%$. The detection of a very clear scattering signal received after 16 minutes reinforces the suspicion that in these minutes a parameter relevant for the scattering must change. In case of a synthesis at $30^{\circ} \mathrm{C}$, there is only a small increase in scattering intensity which indicates only a slight increase in particle density. Thus, it is reasonable to correlate this drastic increase in scattering intensity with an increase in particle density due to a collapse in particle size.

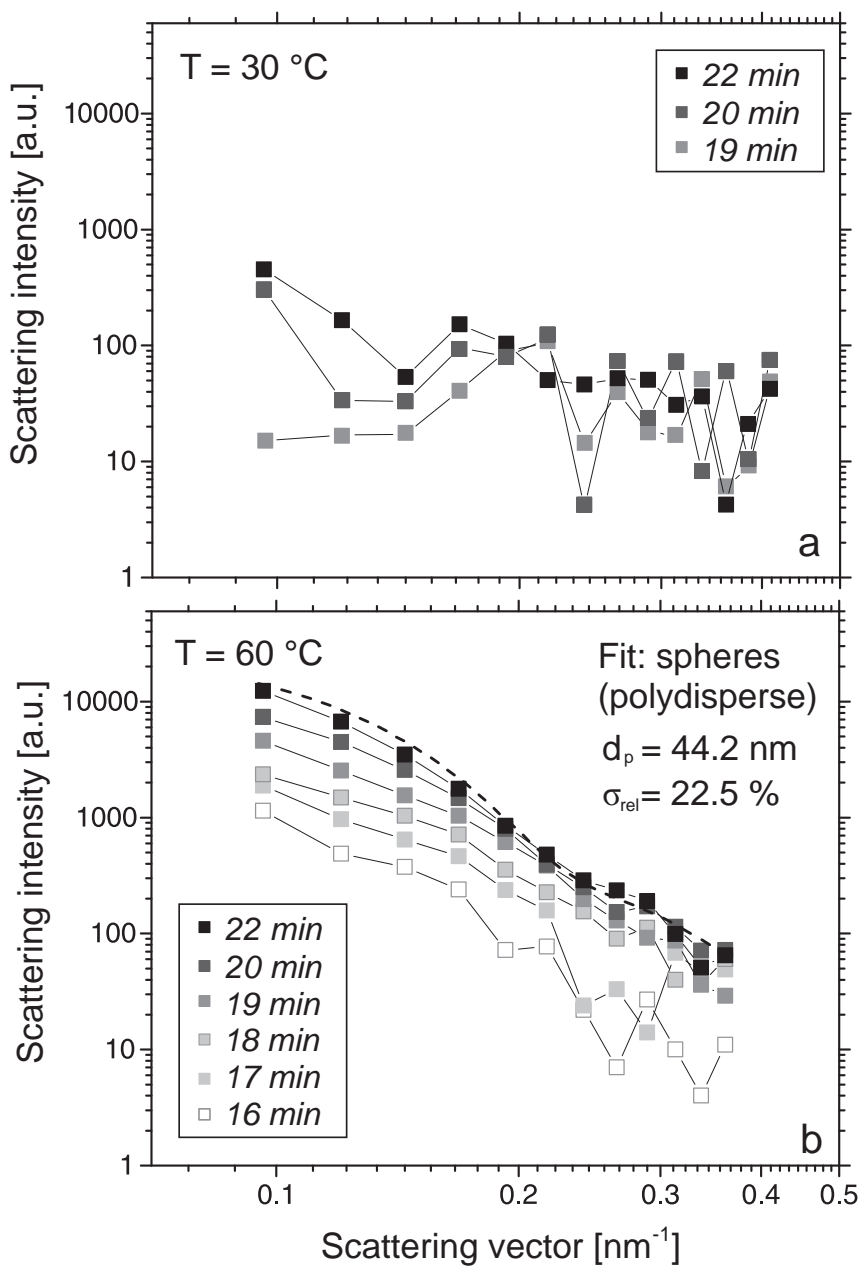

Fig. 11. Time-resolved SAXS data obtained for syntheses run at $30(a)$ and $60^{\circ} \mathrm{C}(\mathrm{b})$. Dashed line: unified fit for polydisperse compact spheres for particles obtained after ${ }^{\circ} \mathrm{C} 22$ minutes reaction time. 


\section{Conclusion}

In this work, we analyzed the formation of porous spherical silica particles without adding any surfactants. The higher the synthesis tem perature, the higher is the specific surface area and the smaller the obtained particle size. At lower temperature levels, the surface rough ness remains almost constant. This leads to the assumption that the characteristic of the particle structure does not change dramatically in this temperature range. At higher synthesis temperatures, an increase of the surface roughness can be observed. The frequency distribution of the pore inlet diameter obtained from the specific surface area indi cates the existence of porous structures, but also a shift to smaller pore inlet diameters at higher synthesis temperatures. The monitoring of the characteristic wavelength shows a collapse in particle size within the first minutes of reaction. The higher the synthesis temperature, the more pronounced the collapse is and the sooner it takes place. The coat ing of inner pores would explain both a decrease in small pores obtained for the frequency distributing of the pore inlet diameter for particles synthetized at low reaction temperatures and a more pronounced clus ter collapse at higher reaction temperatures. It seems reasonable that with lower reaction kinetics the internal densification progresses so far that no collapse is recognizable. Time resolved SAXS data correlate the drastic increase in scattering intensity with an increase in particle density due to a collapse in particle size.

\section{Funding}

The research leading to these results has received funding from the German Research Foundation (DFG Ni 414/22 1 and DFG Ni 414/24 1).

\section{References}

[1] L. Vivar Mora, A. Taylor, S. Paul, R. Dawson, C. Wang, W. Taleb, J. Owen, A. Neville, R. Barker, Impact of silica nanoparticles on the morphology and mechanical properties of sol-gel derived coatings, Surf. Coat. Technol. 342 (2018) 48-56.

[2] F. Chen, G. Hableel, E.R. Zhao, J.V. Jokerst, Multifunctional nanomedicine with silica: Role of silica in nanoparticles for theranostic, imaging, and drug monitoring, J. Colloid Interface Sci. 521 (2018) 261-279.

[3] J. Kecht, A. Schlossbauer, T. Bein, Selective Functionalization of the Outer and Inner Surfaces in Mesoporous Silica Nanoparticles, Chem. Mater. 20 (2008) 7207-7214.

[4] Y.-S. Lin, S.-H. Wu, Y. Hung, Y.-H. Chou, C. Chang, M.-L. Lin, C.-P. Tsai, C.-Y. Mou, Multifunctional Composite Nanoparticles: Magnetic, Luminescent, and Mesoporous, Chem. Mater. 18 (2006) 5170-5172.

[5] S. Kurungot, T. Yamaguchi, S.-i. Nakao, Rh/ $\gamma$-Al2O3 Catalytic Layer Integrated with Sol-Gel Synthesized Microporous Silica Membrane for Compact Membrane Reactor Applications, Catal. Lett. 86 (2003) 273-278.

[6] R. Vacassy, R.J. Flatt, H. Hofmann, K.S. Choi, R.K. Singh, Synthesis of Microporous Silica Spheres, J. Colloid Interface Sci. 227 (2000) 302-315.

[7] S. Klein, S. Thorimbert, W.F. Maier, Amorphous Microporous Titania-Silica Mixed Oxides: Preparation, Characterization, and Catalytic Redox Properties, J. Catal. 163 (1996) 476-488

[8] B. Niu, Y. Zhou, T. Wen, G. Quan, V. Singh, X. Pan, C. Wu, Proper functional modification and optimized adsorption conditions improved the DNA loading capacity of mesoporous silica nanoparticles, Colloids Surf. A Physicochem. Eng. Asp. 548 (2018) 98-107.

[9] A. Zielińska, I. Pereira, S. Antunes, F.J. Veiga, A.C. Santos, I. Nowak, A.M. Silva, E.B. Souto, Chapter 10 - Mesoporous silica nanoparticles as drug delivery systems against melanoma A2 - Grumezescu, Alexandru Mihai, Design of Nanostructures for Theranostics Applications, William Andrew Publishing 2018, pp. 437-466.

[10] A.F. Moreira, D.R. Dias, I.J. Correia, Stimuli-responsive mesoporous silica nanoparticles for cancer therapy: a review, Microporous Mesoporous Mater. 236 (2016) 141-157.

[11] N. Mizoshita, H. Tanaka, Interface-assisted synthesis of mesoporous silica nanoparticles using neat tetraalkoxysilanes, Microporous Mesoporous Mater. 239 (2017) $1-8$.

[12] N. Hee-Kyung, K. Mi-Hee, P. Kihyun, R. Soo-Ryoon, L.K. Eun, J. Hyesung, R. Ryong, H. Changbong, M. Dal-Hee, Efficient Functional Delivery of siRNA using Mesoporous Silica Nanoparticles with Ultralarge Pores, Small 8 (2012) 1752-1761.

[13] H. Yamada, C. Urata, Y. Aoyama, S. Osada, Y. Yamauchi, K. Kuroda, Preparation of Colloidal Mesoporous Silica Nanoparticles with Different Diameters and Their Unique Degradation Behavior in Static Aqueous Systems, Chem. Mater. 24 (2012) 1462-1471.

[14] Y.-S. Lin, C.L. Haynes, Synthesis and Characterization of Biocompatible and SizeTunable Multifunctional Porous Silica Nanoparticles, Chem. Mater. 21 (2009) 3979-3986.
[15] W. Stöber, A. Fink, E. Bohn, Controlled growth of monodisperse silica spheres in the micron size range, J. Colloid Interface Sci. 26 (1968) 62-69.

[16] K.D. Keefer, D.W. Schaefer, Growth of Fractally Rough Colloids, Phys. Rev. Lett. 56 (1986) 2376-2379.

[17] D.W. Schaefer, K.D. Keefer, Structure of Random Porous Materials: Silica Aerogel, Phys. Rev. Lett. 56 (1986) 2199-2202.

[18] D.W. Schaefer, K.D. Keefer, Fractal Geometry of Silica Condensation Polymers, Phys. Rev. Lett. 53 (1984) 1383-1386.

[19] H. Boukari, J. Lin, M. Harris, Probing the dynamics of the silica nanostructure formation and growth by SAXS, Chem. Mater. 9 (1997) 2376-2384.

[20] H. Boukari, J.S. Lin, M.T. Harris, Small-Angle X-Ray Scattering Study of the Formation of Colloidal Silica Particles from Alkoxides: Primary Particles or Not? J. Colloid Interface Sci. 194 (1997) 311-318.

[21] J.K. Bailey, M.L. Mecartney, Formation of colloidal silica particles from alkoxides, Colloids Surf. A Physicochem. Eng. Asp. 63 (1992) 151-161.

[22] C.J. Brinker, G.W. Scherer, Sol $\rightarrow$ gel $\rightarrow$ glass: I. Gelation and gel structure, J. NonCryst. Solids 70 (1985) 301-322.

[23] R.K. Iler, The Colloid Chemistry of Silica and Silicates, Soil Sci. 80 (1955) 86.

[24] Y. Tian, J. Du, D. Hu, W. Zheng, W. Han, Densification effects on porous silica: a molecular dynamics study, Scr. Mater. 149 (2018) 58-61.

[25] C. Noguera, B. Fritz, A. Clément, Precipitation mechanism of amorphous silica nanoparticles: a simulation approach, J. Colloid Interface Sci. 448 (2015) 553-563.

[26] S. Fouilloux, A. Désert, O. Taché, O. Spalla, J. Daillant, A. Thill, SAXS exploration of the synthesis of ultra monodisperse silica nanoparticles and quantitative nucleation growth modeling, J. Colloid Interface Sci. 346 (2010) 79-86.

[27] J.V.L. Beckers, S.W. de Leeuw, Molecular dynamics simulation of nanoporous silica, J. Non-Cryst. Solids 261 (2000) 87-100.

[28] S. Fouilloux, J. Daillant, A. Thill, Single step synthesis of 5-30nm monodisperse silica nanoparticles: Important experimental parameters and modeling, Colloids Surf. A Physicochem. Eng. Asp. 393 (2012) 122-127.

[29] C. Wang, Y. Zhang L. Dong L. Fu, Y. Bai, T. Li, J. Xu, Y. Wei, Two-dimensional ordered arrays of silica nanoparticles, Chem. Mater. 12 (2000) 3662-3666.

[30] C. Tan, B. Bowen, N. Epstein, Production of monodisperse colloidal silica spheres: effect of temperature, J. Colloid Interface Sci. 118 (1987) 290-293.

[31] M. Meier, J. Ungerer, M. Klinge, H. Nirschl, Synthesis of nanometric silica particles via a modified Stöber synthesis route, Colloids Surf. A Physicochem. Eng. Asp. 538 (2018) 559-564

[32] K. Yano, Y. Fukushima, Particle size control of mono-dispersed super-microporous silica spheres, J. Mater. Chem. 13 (2003) 2577-2581.

[33] P. Stephan, K. Schaber, K. Stephan, F. Mayinger, Thermodynamik: Grundlagen und technische Anwendungen - Band 2: Mehrstoffsysteme und chemische Reaktionen, Springer, Berlin Heidelberg, 2018.

[34] A. Gutsche, M. Meier, X. Guo, J. Ungerer, H. Nirschl, Modification of a SAXS camera to study structures on multiple scales, J. Nanopart. Res. 19 (2017) 321.

[35] A. Gutsche, N. Dingenouts, X. Guo, M. Meier, H. Nirschl, Probing the absolute scattering intensity by means of a laboratory-based small-angle X-ray scattering camera using an imaging plate detector, J. Appl. Crystallogr. 49 (2016) 15-23.

[36] X. Guo, K. Gao, A. Gutsche, M. Seipenbusch, H. Nirschl, Combined small- and wideangle X-ray scattering studies on oxide-supported Pt nanoparticles prepared by a CVS and CVD process, Powder Technol. 272 (2015) 23-33.

[37] X. Guo, M. Wagner, A. Gutsche, J. Meyer, M. Seipenbusch, H. Nirschl, Laboratory SWAXS combined with a low-pressure impactor for quasi-online analysis of nanoparticles generated by spark discharge, J. Aerosol Sci. 85 (2015) 17-29.

[38] A. Gutsche, A. Daikeler, X. Guo, N. Dingenouts, H. Nirschl, Time-resolved SAXS characterization of the shell growth of silica-coated magnetite nanocomposites, J. Nanopart. Res. 16 (2014)

[39] V. Goertz, A. Gutsche, N. Dingenouts, H. Nirschl, Small-Angle X-ray Scattering Study of the Formation of Colloidal SiO2Stöber Multiplets, J. Phys. Chem. C 116 (2012) 26938-26946.

[40] V. Goertz, N. Dingenouts, H. Nirschl, Comparison of Nanometric Particle Size Distributions as Determined by SAXS, TEM and Analytical Ultracentrifuge, Part. Part. Syst. Charact. 26 (2009) $17-24$

[41] M.A. Singh, S.S. Ghosh, R.F. Shannon Jnr., A direct method of beam-height correction in small-angle X-ray scattering, J. Appl. Crystallogr. 26 (1993) 787-794.

[42] G. Beaucage, Approximations Leading to a Unified Exponential/Power-Law Approach to Small-Angle Scattering, J. Appl. Crystallogr. 28 (1995) 717-728.

[43] M. Szekeres, J. Tóth, I. Dékány, Specific Surface Area of Stoeber Silica Determined by various Experimental Methods, Langmuir 18 (2002) 2678-2685.

[44] L.T. Zhuravlev, The surface chemistry of amorphous silica. Zhuravlev model, Colloids Surf. A Physicochem. Eng. Asp. 173 (2000) 1-38.

[45] D. Green, S. Jayasundara, Y.-F. Lam, M. Harris, Chemical reaction kinetics leading to the first Stober silica nanoparticles-NMR and SAXS investigation, J. Non-Cryst. Solids 315 (2003) 166-179.

[46] G.H. Bogush, C.F. Zukoski Iv, Studies of the kinetics of the precipitation of uniform silica particles through the hydrolysis and condensation of silicon alkoxides, J. Colloid Interface Sci. 142 (1991) 1-18.

[47] G.H. Bogush, C.F. Zukoski Iv, Uniform silica particle precipitation: an aggregative growth model, J. Colloid Interface Sci. 142 (1991) 19-34.

[48] T. Mizutani, S. Ogawa, T. Murai, H. Nameki, T. Yoshida, S. Yagi, In situ UV-vis investigation of growth of gold nanoparticles prepared by solution plasma sputtering in $\mathrm{NaCl}$ solution, Appl. Surf. Sci. 354 ( (2015) 397-400.

[49] C. Fernández-Blanco, A. Colina, A. Heras, V. Ruiz, J. López-Palacios, Multipulse strategies for the electrosynthesis of gold nanoparticles studied by UV/Vis spectroelectrochemistry, Electrochem. Commun. 18 (2012) 8-11. 
[50] W. Haiss, N.T.K. Thanh, J. Aveyard, D.G. Fernig, Determination of Size and Concentration of Gold Nanoparticles from UV Vis Spectra, Anal. Chem. 79 (2007) 4215-4221

[51] V. Amendola, M. Meneghetti, Size Evaluation of Gold Nanoparticles by UV vis Spectroscopy, J. Phys. Chem. C 113 (2009) 4277-4285.

[52] V.E. Podasca, T. Buruiana, E.C. Buruiana, UV-cured polymeric films containing ZnO and silver nanoparticles with UV-vis light-assisted photocatalytic activity, Appl. Surf. Sci. 377 (2016) 262-273.

[53] D.K. Bhui, H. Bar, P. Sarkar, G.P. Sahoo, S.P. De, A. Misra, Synthesis and UV-vis spectroscopic study of silver nanoparticles in aqueous SDS solution, J. Mol. Liq. 145 (2009) 33-37.

[54] G.A. Martínez-Castañón, N. Niño-Martínez, F. Martínez-Gutierrez, J.R. MartínezMendoza, F. Ruiz, Synthesis and antibacterial activity of silver nanoparticles with different sizes, J. Nanopart. Res. 10 (2008) 1343-1348.
[55] T.V. Pinto, D.M. Fernandes, A. Guedes, C. Silva, C. Pereira, C. Freire, Photochromic polypropylene fibers based on UV-responsive silica@phosphomolybdate nanoparticles through melt spinning technology, Chem. Eng. J.

[56] K.S. Rao, K. El-Hami, T. Kodaki, K. Matsushige, K. Makino, A novel method for synthesis of silica nanoparticles, J. Colloid Interface Sci. 289 (2005) 125-131.

[57] R.B.M. Schasfoort, Handbook of Surface Plasmon Resonance: 2nd Edition, Royal Society of Chemistry2017.

[58] A. Gutsche, X. Guo, N. Dingenouts, H. Nirschl, Synthesis and small angle X-ray scattering (SAXS) characterization of silica spheres covered with gel-like particles formed by means of solvent evaporation, Powder Technol. 278 (2015) 257-265.

[59] P. Schmidt, Small-angle scattering studies of disordered, porous and fractal systems, J. Appl. Crystallogr. 24 (1991) 414-435. 
Karlsruher Institut für Technologie

\section{Repository KITopen}

Dies ist ein Postprint/begutachtetes Manuskript.

Empfohlene Zitierung:

Meier, M.; Ungerer, J.; Klinge, M.; Nirschl, H.

Formation of porous silica nanoparticles at higher reaction kinetics.

2018. Powder technology, 339.

doi: $10.5445 / / R / 1000086526$

Zitierung der Originalveröffentlichung:

Meier, M.; Ungerer, J.; Klinge, M.; Nirschl, H.

Formation of porous silica nanoparticles at higher reaction kinetics.

2018. Powder technology, 339, 801-808.

doi:10.1016/j.powtec.2018.08.069

Lizenzinformationen: CC BY-NC-ND 4.0 